\title{
Is Laparoscopic Adrenalectomy Safe in Large Adrenal Masses?
}

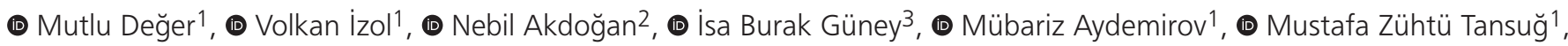 \\ (D) Yıldırım Bayazıt ${ }^{1}$ \\ 'Çukurova University Faculty of Medicine, Department of Urology, Adana, Turkey \\ 2 Mersin Toros State Hospital, Clinic of Urology, Mersin, Turkey \\ 3 Çukurova University Faculty of Medicine, Department of Nuclear Medicine, Adana, Turkey
}

\begin{abstract}
Objective: We aimed to investigate the reliability and effectiveness of laparoscopic adrenalectomy (LA) in large adrenal masses by comparing LA results for large- and small-volume $(<5 \mathrm{~cm})$ masses.

Materials and Methods: Patients who underwent LA due to adrenal mass between February 2004 and December 2018 in our clinic were retrospectively analyzed. The patients were divided into two groups as mass size $<5 \mathrm{~cm}$ (group I) and $\geq 5 \mathrm{~cm}$ (group II). Patients who underwent open adrenalectomy and whose data were not available were excluded from the study. Perioperative data, postoperative results, complications, and histopathological results were examined.

Results: There were 62 patients who underwent LA. Thirty-three patients (53.2\%) had a left adrenal mass, and 29 patients (46.8\%) had a right adrenal mass. Of the 62 adrenal masses, $46(74.2 \%)$ had a diameter of $<5 \mathrm{~cm}$ (group I), and $16(25.8 \%)$ were $\geq 5 \mathrm{~cm}$ (group II). The mean tumor size was $3.2 \pm 0.15$ and $6.4 \pm 3.5 \mathrm{~cm}$ in group I and group II, respectively. There was no statistically significant difference between the groups in terms of age, operative time, and blood loss. The average length of hospital stay was $37.6 \pm 20.9$ hours in group I, while it was $49.8 \pm 22.9$ hours in group II and was significantly longer in group II $(\mathrm{p}<0.05)$. Intraoperative blood pressure elevation occurred in one patient in group I and II. In a patient with suspected malignancy in group II, the surgery was shifted to open surgery as the capsule over the mass was opened. Hypopotasemia was observed in one patient, and atelectasis was observed in one patient in group I, and pneumonia was observed in one patient in group II.

Conclusion: LA is a minimally invasive surgical method that can be applied safely in experienced centers in masses larger than $5 \mathrm{~cm}$ with no suspected invasion in preoperative imaging.
\end{abstract}

Keywords: Adrenal mass, laparoscopy, laparoscopic adrenalectomy, large adrenal masses

\section{Introduction}

In 1992, laparoscopic adrenalectomy (LA) was first used by Gagner et al. (1) in a patient with Cushing's syndrome. Developing to date, it has been the preferred method of surgical treatment of various adrenal masses, including dysfunctional adenoma, pheochromocytoma, Cushing's disease, aldosteronoma, myelolipoma, and cysts $(2,3)$.

Laparoscopic treatment of large adrenal masses is alarming due to the risk of malignancy and technical difficulties $(4,5)$. The size criterion is one of the main issues discussed for the laparoscopic approach in adrenal lesions. For LA, an exact upper limit has not been defined in terms of mass size. Data obtained in the last 15 years show that the laparoscopic approach is feasible and successful for lesions smaller than $5 \mathrm{~cm}$ (6). It has been reported that the size of the adrenal mass in preoperative imaging should not be the primary factor in determining laparoscopic indication (7). In this study, we aimed to investigate the reliability and effectiveness of LA in large adrenal masses by comparing the perioperative and postoperative results of patients with a mass of $<5 \mathrm{~cm}$ and those with a mass of $\geq 5 \mathrm{~cm}$, who underwent LA.

Cite this article as: Değer M, İol V, Akdoğan N, Güney IB, Aydemirov M, Tansuğ MZ, Bayazıt Y. Is Laparoscopic Adrenalectomy Safe in Large Adrenal Masses? Bull Urooncol 2020;19(1):7-11 


\section{Materials and Methods}

Sixty-two patients who underwent LA due to adrenal mass in our clinic between February 2004 and December 2018 were retrospectively reviewed. Detailed anamnesis was obtained from all patients, and a physical examination was performed. Patients were evaluated with computed tomography (CT) and/or magnetic resonance imaging (MRI) and F-18 FDG positron-emission tomography/CT imaging, if necessary. All patients were consulted with the Endocrinology Clinic to evaluate the function of the adrenal mass. In addition to the complete blood count and routine biochemical tests, serum electrolytes, adrenocorticotropic hormone, cortisol, aldosterone, renin, dehydroepiandrosterone sulfate, arterial blood gas, and 5-hydroxy indole acetic acid, metanephrine, normetanephrine, homovanilic acid, vanyl mandelic acid, adrenaline and noradrenaline in 24-hour urine were performed according to the clinical features of the patients to determine whether the adrenal mass was functional or not. Plasma metanephrine levels were evaluated in patients with high catecholamine degradation products in 24 hours of urine. All patients underwent a $1 \mathrm{mg}$ dexamethasone suppression test. 24-hour urine cortisol levels were also examined in patients with suspected Cushing's disease. Patients with surgical indications (hormone active, suspicious of malignancy, or mass larger than four centimeters) underwent LA by an experienced team.

The patients were divided into two groups as mass size $<5$ (group I) and $\geq 5 \mathrm{~cm}$ (group II). Patients who had open adrenalectomy and whose data could not be accessed were excluded from the study. All intraoperative and postoperative parameters were retrieved from adrenalectomy data and hospital information systems, where data has been recorded regularly since 2004 and evaluated retrospectively. Demographic features, tumor sizes, duration of surgery, intraoperative and postoperative complications, length of hospital stay, and histopathological features were examined.

Ethics committee approval was received for this study from the Ethics Committee of Çukurova University (approval number: June 2019, 89/49).

\section{Laparoscopic Adrenalectomy Technique}

All patients underwent LA by transperitoneal route after obtaining informed consent. On the day before the operation, intestinal preparation was made with a clear liquid diet and laxatives. For pre-diagnosed functional pheochromocytoma, beta-blocker (propranolol $1 \times 40 \mathrm{mg}$ or metoprolol succinate $2 \times 50 \mathrm{mg}$ ) and alpha-blocker (doxazosin $2 \times 4 \mathrm{mg}$ ) treatment were started two weeks before the surgery. In these cases, phentolamine (alpha 1 + alpha 2 adrenergic blocker) was available for a possible hypertensive crisis during the surgery. In all cases, prophylactic first-generation cephalosporin was administered one hour before surgery, and general anesthesia with endotracheal intubation was performed. Modified $\left(60^{\circ}\right)$ lateral decubitus position was used in patients with right adrenal mass, and lateral decubitus position was used in patients with a left adrenal mass. The upper arm was fixed to the patient's posterolateral to protect the brachial plexus. The patients were covered so that we could switch to open surgery if necessary. On the pararectal line, a $1.2 \mathrm{~cm}$ long transverse incision was made to the $2-5 \mathrm{~cm}$ cranial of the umbilicus, and the abdomen was entered with a Veress needle. Carbon dioxide pneumoperitoneum was created so that intraperitoneal pressure was $16-18 \mathrm{~mm} \mathrm{Hg}(12-14 \mathrm{~mm} \mathrm{Hg}$ in those with suspected pheochromocytoma). An $11 \mathrm{~mm}$ port was inserted bluntly by canceling the blade in the umbilicus through the incision to accommodate the camera. Thirty degree lenses were used in surgeries.

For left adrenalectomy, two subcostal $5 \mathrm{~mm}$ ports are placed; one in the midclavicular line and the other in the pararectal line. After the trocars were placed, the working pressure was set to $12 \mathrm{mmHg}$ (10 $\mathrm{mmHg}$ for those with suspected pheochromocytoma).

On the left, the Toldt line was first incised. The phrenocolic and splenocolic ligaments were cut, and the colon was reflected medially. Posterior peritoneal dissection was carried out between the lateral spleen and upper stomach. The dissection was completed by incising the splenorenal ligament, and the spleen was allowed to fall away cranially with its own weight. At this stage, the upper part of the adrenal gland was freed entirely from the spleen and superomedially from the pancreas, the entire upper dissection was completed from the posterior diaphragm to the quadratus lumborum muscle, and the upper part of the adrenal gland was released. The upper pole of the kidney and renal hilum were visualized. The left adrenal vein pouring into the renal vein was found and clipped. The inferior part of the adrenal gland was freed entirely by opening the Gerot's fascia and dissecting between the adrenal gland and the upper pole of the kidney, and then adrenalectomy was completed by medial, posterior, and lateral dissection.

In the right adrenalectomy, after the triangular ligament was cut, a $5 \mathrm{~mm}$ trocar was placed $1-2 \mathrm{~cm}$ below the xiphoid for liver retraction in addition to the ports on the left. A laparoscopic locking grasper was placed in a way to retract the inferior edge of the liver anterosuperiorly and was locked to the lateral wall of the abdomen. In the posterior peritoneum, an incision was made starting from the cecum at the bottom and lateral of the ascending colon and extending to the posteroinferior edge of the liver along the lateral edge of the duodenum. The duodenum was reflected medially, and vena cava and right renal vein were visualized. After the inferomedial corner of the adrenal gland was mobilized by dissection at the junction of the renal vein and vena cava, the surgery was extended to the liver by dissection between the lateral edge of the vena cava and the medial edge of the adrenal gland. After finding the right adrenal vein in the posterolateral side of vena cava, it was clipped and cut. Lateral dissection was performed between the inferior edge of the liver and the superior edge of the adrenal gland, and then the posterior part of the adrenal gland was freed. Finally, adrenalectomy was completed by dissection from medial to the lateral between the superior pole of the kidney and the inferior edge of the adrenal gland. In cases diagnosed with pheochromocytoma, the adrenal vein was clipped as early as possible on both sides.

The adrenal gland was placed in the specimen bag and was removed by enlarging the $11 \mathrm{~mm}$ trocar incision or by making 
an incision at the lateral end of the Pfannenstiel incision in female patients who had a previous cesarean section. In cases where the surgeon did not need, a drain was not placed, and one drain was placed in the others.

In the postoperative period, patients were mobilized as early as possible, analgesics were applied when necessary, and oral feeding was initiated according to intestinal functions. Patients without problems were discharged on the first postoperative first day after their drains were removed. They were followed by the departments of urology and endocrinology, according to the histopathological examination results and clinical status.

\section{Statistical Analysis}

SPSS 23 was used for statistical analysis of the data. Categorical data were summarized as numbers, while numerical data were summarized as mean and standard deviation. A chi-square test was used to compare categorical data between groups. The Kolmogorov-Smirnov test determined whether the numerical data met the normal distribution assumption. Independent samples t-test was used for comparison of numerical data between groups if assumptions were met, and the MannWhitney-U test was used if assumptions were not met. The statistical significance level was set as $<0.05$ in all tests.

\section{Results}

Of the 62 patients undergoing LA, 43 (69.3\%) were female, and $19(30.7 \%)$ were male. Thirty-three patients (53.2\%) had a left adrenal mass, and 29 patients $(46.8 \%)$ had a right adrenal mass. Of the 62 adrenal masses, $46(74.2 \%)$ were $<5 \mathrm{~cm}$ in diameter (group I), and 16 (25.8\%) were $\geq 5 \mathrm{~cm}$ (group II). The demographic data of patients in the groups are summarized in Table 1. The mean tumor size was $3.2 \pm 0.15 \mathrm{~cm}$ (range: $1-4.9 \mathrm{~cm}$ ) and $6.4 \pm 3.5 \mathrm{~cm}$ (range: $5-10 \mathrm{~cm}$ ) in group I and group II, respectively (Table 1 ). Surgical indications in group I were mass size in 11 patients (23.9\%), functional mass in 21 patients (45.6\%), and suspicion of malignancy in 14 patients (30.4\%). Surgical indications in group II were mass size in 10 patients (62.5\%), functional mass in three patients $(18.7 \%)$, and suspicion of malignancy in three patients (18.7\%).

\begin{tabular}{|c|c|c|c|}
\hline & $<5 \mathrm{~cm}$ & $\geq 5 \mathrm{~cm}$ & $p$ \\
\hline Number of the patients & $46(74.2 \%)$ & $16(25.8 \%)$ & - \\
\hline \multicolumn{4}{|l|}{ Gender n (\%) } \\
\hline Male & $34(73.9 \%)$ & $9(56.2 \%)$ & \multirow[t]{2}{*}{0.22} \\
\hline Female & $12(26.0 \%)$ & $7(43.7)$ & \\
\hline \multicolumn{4}{|l|}{ Side } \\
\hline Right & $19(41.3 \%)$ & $10(62.5 \%)$ & \multirow[t]{2}{*}{0.16} \\
\hline Left & $27(58.6 \%)$ & $6(37.5 \%)$ & \\
\hline Age (year) & $46.1 \pm 12.7$ & $47 \pm 12.5$ & 0.83 \\
\hline $\mathrm{BMI}^{*}\left(\mathrm{~kg} / \mathrm{m}^{2}\right)$ & $27.5 \pm 3.8$ & $30.4 \pm 7.3$ & 0.62 \\
\hline Size of the tumor $(\mathrm{cm})$ & $3.2 \pm 0.15$ & $6.4 \pm 3.5$ & 0.01 \\
\hline
\end{tabular}

The mean operative time was 101.2 \pm 21.8 and $107.4 \pm 25.4$ minutes in group I and group II, respectively, and there was no statistically significant difference between the groups in terms of mean operative time $(p=0.31)$ (Table 2$)$. The mean amount of bleeding was $49.5 \pm 12.7$ and $94.3 \pm 40.2$ in group I and group II, respectively (Table 2 ). The bleeding amount of group II was higher than group I, but there was no statistically significant difference $(p=0.14)$. Only one of the patients in group II received one unit of blood transfusion in the perioperative period. The mean length of hospital-stay in group I was 37.6 \pm 20.9 hours, while it was $49.8 \pm 22.9$ hours in group II and was statistically significantly longer in group II $(p<0.05)$ (Table 2$)$.

One of the patients in group I also underwent simultaneous partial nephrectomy due to the ipsilateral renal mass. In group II, one of the patients underwent simultaneous renal cyst excision, and one of the patients underwent simultaneous psoas abscess drainage.

Complications are shown in Table 3. According to the modified Clavien-Dindo Classification, there were two grade 2 complications in group I and one grade 2 complications in group II. Intraoperative blood pressure elevation occurred in one patient in each group. Blood pressure returned to typical values after the adrenal vein was clipped. In a patient with suspected malignancy in group II, the surgery was shifted to open surgery as the capsule of the mass was opened. One patient in group I developed hypopotasemia, and one patient had atelectasis, and one patient in group II developed pneumonia.

Histopathological results in both groups are shown in Table 4. According to histopathology reports, there were 42 benign (91.3\%), three malignant (6.5\%) lesions and one borderline (2.1\%) lesion in group I, and 14 benign (87.5\%) and two malignant (12.5\%) lesions in group II. When the two groups were compared in terms of malignancy, there was no statistically significant difference $(p=0.46)$.

A patient with adrenal cortical carcinoma had a reported capsule invasion as a result of histopathology, and the patient

Table 2. Difference between the groups in terms of mean operative time

\begin{tabular}{|l|l|l|l|}
\hline & $<5 \mathrm{~cm}$ & $\geq 5 \mathrm{~cm}$ & $\mathbf{p}$ \\
\hline Duration of the operation $(\mathrm{min})$ & $101.2 \pm 21.8$ & $107.4 \pm 25.4$ & 0.3 \\
\hline Amount of bleeding $(\mathrm{mL})$ & 49.5 & 94.3 & 0.14 \\
\hline Blood tranfusion, $\mathrm{n}(\%)$ & 0 & $1(6.25 \%)$ & 0.08 \\
\hline Discharge time $(\mathrm{min})$ & $37.6 \pm 20.9$ & $49.8 \pm 22.9$ & 0.05 \\
\hline
\end{tabular}

\begin{tabular}{|c|c|c|}
\hline & $<5 \mathrm{~cm}$ & $\geq 5 \mathrm{~cm}$ \\
\hline Perioperative complications, $\mathrm{n}(\%)$ & $1(2.1 \%)$ & $2(12.5 \%)$ \\
\hline Perioperative hypertension & $1(2.1 \%)$ & $1(6.2 \%)$ \\
\hline Opening the capsule & 0 & $1(6.2 \%)$ \\
\hline Postoperative complications, n (\%) & $2(4.3 \%)$ & $1(6.2 \%)$ \\
\hline Hypopotassemia & $1(2.1 \%)$ & 0 \\
\hline Atelectasis & $1(2.1 \%)$ & 0 \\
\hline Pneumonia & 0 & $1(6.2 \%)$ \\
\hline
\end{tabular}




\begin{tabular}{|l|l|l|}
\hline \multicolumn{4}{|l|}{ Table 4. Histopathological results in both groups } \\
\hline Histopathology & $<5 \mathrm{~cm}$ & $\geq 5 \mathrm{~cm}$ \\
\hline Adrenale cortical neoplasia, $\mathrm{n}(\%)$ & $18(39.1 \%)$ & $3(18.7 \%)$ \\
\hline Adrenale hyperplasia, $\mathrm{n}(\%)$ & $11(23.9 \%)$ & 0 \\
\hline Phaeochromocytoma, $\mathrm{n}(\%)$ & $6(13.0 \%)$ & $2(12.5 \%)$ \\
\hline Myelolipoma, $\mathrm{n}(\%)$ & $4(8,6 \%)$ & $5(31.2 \%)$ \\
\hline Adrenale cortical carcinoma, $\mathrm{n}(\%)$ & $1(2.1 \%)$ & $1(6.2 \%)$ \\
\hline Metastasic renal cell carcinoma, $\mathrm{n}(\%)$ & $1(2.1 \%)$ & 0 \\
\hline Oncocytic adrenale cortical neoplasia, $\mathrm{n}(\%)$ & $1(2.1 \%)$ & 0 \\
\hline Vascular cyst, $\mathrm{n}(\%)$ & $1(2.1 \%)$ & 0 \\
\hline Ganglioneuroblastoma, $\mathrm{n}(\%)$ & $1(2.1 \%)$ & 0 \\
\hline Epithelial cyst, $\mathrm{n}(\%)$ & $1(2.1 \%)$ & 0 \\
\hline Simple kist, $\mathrm{n}(\%)$ & $1(2.1 \%)$ & 0 \\
\hline Hemangioma, $\mathrm{n}(\%)$ & 0 & $2(12.5 \%)$ \\
\hline Metastasic urethral carcinoma, $\mathrm{n}(\%)$ & 0 & $1(6.2 \%)$ \\
\hline Hemorrhagic cyst, $\mathrm{n}(\%)$ & 0 & $1(6.2 \%)$ \\
\hline Endothelial cyst, $\mathrm{n}(\%)$ & 0 & $1(6.2 \%)$ \\
\hline
\end{tabular}

was followed up closely, and no recurrence was observed during follow-up. Adjuvant radiotherapy and chemotherapy were initiated in the histopathology report of the patient, who was shifted to open surgery due to opening the capsule, upon microscopic invasion at the surgical margins. The patient's chemotherapy is still ongoing. Other patients had no postoperative margin positivity as a result of histopathology. Our mean follow-up was $2.3 \pm 1.8$ years. Twenty-one patients did not attend regular follow-up. No problems were encountered in the patients during follow-up.

\section{Discussion}

LA has rapidly gained popularity since its description by Gagner et al. (1). LA offers less perioperative morbidity and mortality, shorter hospital-stay, better cosmetics, and better clinical results compared to the open technique (8). However, LA remains a challenging operation for large adrenal masses. Although data obtained in the past 15 years have shown that the laparoscopic approach is feasible and successful for lesions $<5$ centimeters, size criteria are a current discussion topic for laparoscopic approaches in adrenal lesions $(6,9,10)$. Due to technical difficulties, local recurrence due to possible capsular rupture and risks of incomplete resection, most surgeons are rightly concerned about applying LA for large adrenal masses (11).

In a study where they examined the LA results in adrenal masses larger than $5 \mathrm{~cm}$, Hemal et al. (7) reported that the size of the adrenal mass in preoperative imaging alone should not be the primary factor in determining laparoscopy indication; and that LA for adrenocortical cancers could be performed safely and effectively in a selected group. Tsuru et al. (12) compared LA results in $\geq 5 \mathrm{~cm}$ and $<5 \mathrm{~cm}$ tumors and stated that the operative time, blood loss, and oral feeding onset times were similar, but that the postoperative recovery period was significantly longer in large tumors. Parnaby et al. (13) compared LA results applied to adrenal masses larger and smaller than $6 \mathrm{~cm}$ in 101 patients and concluded that LA results were comparable if there was no local invasion detected by preoperative imaging methods. They stated that local invasion of adrenal masses could be accurately evaluated with CT and MRI and that open adrenalectomy was appropriate in case of local invasion (13). In a study by Novitsky et al. (14) with 24 patients who underwent LA for adrenal masses larger than $5 \mathrm{~cm}$, the mean mass diameter was 6.8 $\mathrm{cm}$, and the mean operative time was 178 (range: 120-300) minutes and no shift to open surgery was reported. The authors found that the advantages that were advocated as a classic for LA were preserved despite the increase in mass size. The authors concluded that LA is indicated for large tumors of $5-10 \mathrm{~cm}$ in the absence of adhesions or infiltration (12).

In the study of Bozkurt et al. (11) in adrenal masses larger than $8 \mathrm{~cm}$ undergoing LA, one surgery was shifted to open surgery, two patients had spleen capsule laceration, and one patient had a liver capsule laceration. They reported Clavien grade 1 postoperative complications in two patients and Clavien grade 2 complications in two patients. In their study in masses larger than $6 \mathrm{~cm}$, Agrusa et al. (10) reported that there was bleeding due to spleen injury in one patient and perirenal hematoma in one patient. In our study, one LA surgery in group II was shifted to open surgery due to the opening of the capsule, intraoperative blood pressure increased in one patient, and Clavien grade 2 complication occurred in one patient. Our results were found to be compatible with the literature.

There are many multicenter studies comparing transperitoneal and retroperitoneal LA surgical results, and both techniques have been reported to have their own advantages and disadvantages $(15,16,17,18)$. The transperitoneal approach has advantages such as providing a wide surgical area and direct access to the adrenal vessels. In this approach, the risk of injury in the intraperitoneal organs is higher. In the retroperitoneal approach, it is advantageous that there is no relation with the intraabdominal organs, and the narrowness of the area and the lack of distinctive anatomical areas during surgery are the disadvantages of this method (19). The retroperitoneal approach is recommended for small adrenal adenomas (20). In the study of Hemal et al. (7), despite the retroperitoneal approach in seven patients, it was stated that the transperitoneal approach was suitable for large adrenal tumors and adrenal carcinomas. In our study, all surgeries were performed with a transperitoneal approach. In this approach, we think that the larger viewing area of the adrenal gland and its surroundings and direct access angles of hand tools compared to the retroperitoneoscopic approach increase the ease of work and safety.

According to the National Institute of Health consensus, the incidence of adrenal cortical carcinoma is $2 \%$ in tumors $<4 \mathrm{~cm}$, $6 \%$ in tumors $41-60 \mathrm{~mm}$, and $25 \%$ for tumors larger than $6 \mathrm{~cm}$ (21). In our study, histopathology of adrenal masses larger than $5 \mathrm{~cm}$ revealed pheochromocytoma in two patients (12.5\%) and malignancy in two patients (12.5\%). Malignancy rates in our study seem to be consistent with the literature. It has been reported in different series that $74-95 \%$ of pheochromocytomas are benign (22). In this case, adopting only the size of the mass as a criterion in the selection of the most appropriate surgical approach may lead to unnecessarily open adrenalectomy in many patients with a benign adrenal mass. The results of our study showed that laparoscopic approach indications in large adrenal masses could vary depending on the surgeon's 
experience and skill and that the mass size alone was not an absolute criterion for laparoscopy.

The limitations of the study were that the study was retrospective and single-centered.

\section{Conclusions}

LA is a minimally invasive surgical method that can be applied safely in experienced centers for masses larger than $5 \mathrm{~cm}$ and where there is no doubt of invasion in preoperative imaging.

\section{Acknowledgements}

Publication: The results of the study were not published in full or in part in form of abstracts.

Contribution: There is not any contributors who may not be listed as authors.

Conflict of Interest: No conflict of interest was declared by the authors.

Financial Disclosure: The authors declared that this study received no financial support.

\section{Ethics}

Ethics Committee Approval: Retrospective study.

Informed Consent: Retrospective study.

Peer-review: Externally peer-reviewed.

\section{Authorship Contributions}

Concept: M.D., Design: M.D., Y.B., V.İ., Data Collection or Processing: M.D., M.A., N.A., Analysis or Interpretation: M.D., Y.B., V.I., M.Z.T., Literature Search: M.D., M.A., N.A., Writing: M.D.

\section{References}

1. Gagner M, Lacroix A, Bolte E. Laparoscopic adrenalectomy in Cushing's syndrome and pheochromocytoma. N Engl J Med 1992;327:1033.

2. Gill IS. The case for laparoscopic adrenalectomy. J Urol 2001;166:429-436.

3. Alemanno G, Bergamini C, Prosperi P, Valeri A. Adrenalectomy: indications and options for treatment. Updates Surg 2017;69:119-125.

4. Parnaby CN, Chong PS, Chisholm L, Farrow J, Connell JM, O'Dwyer PJ. The role of laparoscopic adrenalectomy for adrenal tumours of 6 cm or greater. Surg Endosc 2008;22:617-621.

5. Zografos GN, Farfaras A, Vasiliadis G, et al. Laparoscopic resection of large adrenal tumors. JSLS 2010;14:364-368.
6. Rosoff JS, Raman JD, Del Pizzo JJ. Laparoscopic adrenalectomy for larde adrenal masses. Curr Urol Rep 2008;9:73-79.

7. Hemal AK, Singh A, Gupta NP. Whether adrenal mass more than 5 $\mathrm{cm}$ can pose problem in laparoscopic adrenalectomy? An evaluation of 22 patients. World J Urol 2008;26:505-508.

8. Hazzan D, Shiloni E, Golijanin D, Jurim O, Gross D, Reissman P. Laparoscopic vs open adrenalectomy for benign adrenal neoplasm. Surg Endosc 2001;15:1356-1358.

9. Liao $\mathrm{CH}$, Chueh SC, Lai MK, Hsiao PJ, Chen J. Laparoscopic adrenalectomy for potentially malignant adrenal tumors greater than 5 centimeters. J Clin Endocrinol Metab 2006;91:3080-3083.

10. Agrusa A, Romano G, Frazzetta G, et al. Laparoscopic adrenalectomy for large adrenal masses: single team experience. Int J Surg 2014;12 Suppl 1:S72-74.

11. Bozkurt IH, Arslan M, Yonguc T, et al. Laparoscopic adrenalectomy for large adrenal masses: Is it really more complicated? Kaohsiung | Med Sci 2015;31:644-648.

12. Tsuru N, Suzuki K, Ushiyama T, et al. Laparoscopic adrenalectomy for large adrenal tumors. J Endourol 2005;19:537-540.

13. Parnaby CN, Chong PS, Chisholm L, Farrow J, Connell JM, O'Dwyer PJ. The role of laparoscopic adrenalectomy for adrenal tumours of 6 cm or greater. Surg Endosc 2008;22:617-621.

14. Novitsky YW, Czerniach DR, Kercher KW, Perugini RA, Kelly IJ, Litwin DE. Feasibility of laparoscopic adrenalectomy for large adrenal masses. Surg Laparosc Endosc Percutan Tech 2003;13:106-110.

15. Chiang PH, Yu CJ, Lee WC, Wang HJ, Hsu WC. Comaprasion of retroperitoneoscopic and transperitoneal laparoscopic adrenalectomy for righted-sided benign tumors: a single-institute experience. Urol Int 2015;94:144-148.

16. Naya $Y$, Nagata $M$, Ichilawa $T$, et al. Laparoscopic adrenalectomy: comparison of transperitoneal and retroperitoneal approaches. BJU Int 2002;90:199-204.

17. Ramacciato G, Nigri GR, Petrucciani N, et al: Minimally invasive adrenalectomy: a multicenter comparison of transperitoneal and retroperitoneal approaches. Am Surg 2011;77:409-416.

18. Giger U, Vonlanthen R, Michel JM, Krähenbühl L. Trans- and retroperitoneal endoscopic adrenalectomy: experience in 26 consecutive adrenalectomies. Dig Surg 2004;21:28-32.

19. Kaygısız O, Kordan Y, Yavaşcaoğlu I. Laparoskopik Adrenalektomi. Endoüroloji Bülteni 2015;8:31-36.

20. Prager G, Heinz-Peer G, Passler C, Kaczirek K, Scheuba C, Niederle B. Applicability of laparoscopic adrenalectomy in a prospective study in 150 consecutive patients. Arch Surg 2004;139:46-49.

21. NIH state-of-the-science statement on management of the clinically inapparent adrenal mass ("incidentaloma"), NIH Consens. State Sci. Statements 19 (2002) 1e25. https://consensus.nih. gov/2002/2002Adrenallncidentalomasos021 Program.pdf

22. Zografos GN, Vasiliadis G, Farfaras AN, Aggeli C, Digalakis M. Laparoscopic surgery for malignant adrenal tumors. JSLS 2009; 13:196-202. 